\title{
Student-led podcasting for engineering education
}

\section{E. Alpay \& S. Gulati}

To cite this article: E. Alpay \& S. Gulati (2010) Student-led podcasting for engineering education, European Journal of Engineering Education, 35:4, 415-427, DOI: 10.1080/03043797.2010.487557

To link to this article: http://dx.doi.org/10.1080/03043797.2010.487557

曲 Published online: 08 Jun 2010.

Submit your article to this journal $\pi$

Џ Article views: 127

Q View related articles $₫$

4 Citing articles: 8 View citing articles 준 


\title{
Student-led podcasting for engineering education
}

\author{
E. Alpay* and S. Gulati \\ Faculty of Engineering, Imperial College London, Rm. B303c Bessemer Building, South Kensington \\ Campus, London SW7 2AZ, UK
}

(Received 21 September 2009; final version received 19 April 2010)

\begin{abstract}
The use of podcasts is challenging traditional communication methods in higher education, with the potential for creating engaging and flexible resources for learning and development. Likewise, podcasts are helping to facilitate a stronger student identity and community within learning environments, replacing traditional student newsletter and website approaches. In this work, an innovative podcasting approach is presented in which there is a strong student-centred and student-led premise to foster and advance engineering education-related uses. Podcasts are intended to cover a range of relevant engineering topics, such as sharing student views on global, institutional and scientific developments and disseminating information on unique educational opportunities. Details on the design, set-up and implementation of the initiative are presented (e.g. resource requirements, management and organisation structures, maintenance of balanced educational outcomes). An evaluation of the experiences of the team members is also presented, showing favourable outcomes in skills development, community identity and broader educational awareness.
\end{abstract}

Keywords: podcasting; student-led projects

\section{Introduction}

Personal on demand broadcasts (podcasts) are audio or digital video media files available to be downloaded via the Internet to media players such as iPods or personal computers. They are typically viewed directly on a website or by syndicated download or web feeds. Soon after the inception of podcasting and the rapid adoption and growth of the medium, podcasting advocates suggest it will be a transformative technology for higher education (Campbell 2005). As such, there has been a growing interest in studying how podcasting can be used effectively as a learning tool. This is evidenced by the formation of the Informal Mobile Podcasting and Learning Adaptation project, which is a UK-wide study on the impact of podcasting on student learning in higher education and how the beneficial effects can positively be enhanced (Edirisingha and Salmon 2007). A natural educational use for podcasts has been for distance education courses (Maag 2006). In fact, podcasting has been used to reduce the effects of isolation and promote inclusion for distance learners (Lee and Chan 2007). The use of podcasting is also rising as a campus-based course learning tool (Dale 2007, Edirisingha and Salmon 2007, Liu et al. 2008). Video podcasts

\footnotetext{
*Corresponding author. Email: e.alpay@imperial.ac.uk 
have been found to be beneficial in an engineering course where, in addition to entire lectures, supplemental materials were also published (Kao 2008).

McGarr (2009), in a review of podcasting in higher education, classifies their use as substitutional, supplementary and creative (i.e. student generated). The most common use of podcasts is reported by the author as recordings of past lectures (substitutional), followed by postings of additional study and support material (substitutional). The purpose of such podcasts can be seen as 'enhancing the flexibility of learning, increasing accessibility to learning and enhancing the student's learning experience' (McGarr 2009). However, as discussed by the author, formal research evaluation of the influence of podcasts on student learning is limited. Several studies indicate favourable student attitudes towards the benefits of podcasts, e.g. as supporting material for lectures and textbooks or as revision aids (Huntsberger and Stavitsky 2006, Lee and Chan 2007; see also the discussions of McGarr 2009).

Interestingly, mixed opinions remain on the use of podcasts for social learning. For example, Mackey and Freyberg (2010) indicate that too much dependence on online learning resources may reduce student satisfaction of the learning process, even with the use of real-time audio-visual technology. It is not surprising, therefore, that some studies have shown a student preference to learning through face-to-face contact, with actual student use of podcasts for revision or understanding-support rather than the physical substitution of lectures (see e.g. Copley 2007). However, as discussed by Dale (2007), other researchers have suggested that podcasts can lead to greater social networking, collaborative learning and inclusivity. Such differences in findings suggest that, like other educational content, how podcasts are blended into existing learning frameworks (e.g. lectures, tutorials, group work, assessment) is important, with due attention needed on both cognitive and affective learning support.

As noted by Lee et al. (2008), few podcasting efforts in higher education have gone beyond the mode of passively consumed content produced by faculty as supplemental class material to one that promotes engagement and active learning by shifting the production of the podcasts to the students. A few studies have implemented student-produced podcasts as required projects within courses with implementations such as interviews of experts in a given field (Frydenberg 2006, Armstrong et al. 2009), interviews and discussions among students on topics in the course (Lee et al. 2008, Nie et al. 2008) and for reviewing the historical and technological interest of local engineering structures (C. O'Sullivan et al. 2010, personal communication). Studies of such student-created podcasts have also indicated that the approach not only promotes understanding, e.g. through greater reflection on and engagement with the learning material, but also the development of communication and team-working skills. In a similar way, digital stories (i.e. image-enhanced audio recordings of student experiences) can also facilitate experiential learning through reflection and verbalisation. For example, Jenkins and Lonsdale (2007) report on the use of digital stories for documenting student experiences of the first week at university and, subsequently, much student learning from the school-university transition experience. With the advent of affordable and portable digital video technologies, the wider use of the video format in both formative and summative assessment is likely.

Within Imperial College London (as at other universities), considerable efforts are being made to further enthuse students towards a career in engineering, raise the student awareness as to their potential impact on the big issues (e.g. climate change, population growth, renewable and alternative energy), develop and disseminate activities for global skills development and encourage interdisciplinary work approaches through design projects and real-life experiences (see Alpay et al. 2008). An example of one approach has been the facilitation and support of student-led projects, i.e. through the Student-Led Projects Scheme (see www3.imperial.ac.uk/envision/experiences/studentledschemes). The scheme provides students with academic, administrative and financial support in the development of extra-curricular projects of interest to them and, where relevant, advice on continued project funding and management. 
In line with such developments, this work extends the concept of student-created podcasts for learning to engineering-wide applications through the set-up of a student-led podcasting group. Specifically, undergraduate engineering students (volunteers) across all disciplines oversee the entire podcast production process, from concept to creation and distribution. The podcasts cover engineering-related topics of interest to their peers and teaching staff and open opportunities for new methods of student engagement and involvement in educational topics, debates and developments. This approach can thus be seen as both supplementary and creative, whereby students lead on the development of motivational, informative and educational topics, but through an interface of staff and peer input for online resource development. In doing so, all students are provided with a medium to broaden their social, political and technical awareness through engagement with common and topical issues of relevance to the engineering fraternity as a whole.

In this paper, attention is given to the design and implementation of the student-led podcasting group. Fundamental questions on the appeal of the project to student volunteers (i.e. their motivations for podcasting-related work) and the subsequent impact of the experience on their skills, knowledge and engineering-community development are also considered. Insights for such issues are of course important for the subsequent continuation (sustainability) of the student-led podcasting activity. As a case study, the general methodologies and organisational structures of the student-led podcasting group will be of interest to educators considering the set-up of a similar programme.

\section{Methodology}

\subsection{Project design}

Unlike most implementations of podcasting in education, which consist of posting videos of lectures and supplementary material for courses, in this project the students inspire the educational topics and create the content of the podcasts themselves. Such a strategy not only promotes experiential learning for the student team itself, but also fosters student motivation and active engagement to provide the sustainable delivery of a podcasting service, which has strong links between students and academic staff.

As shown in Figure 1, the project was designed to span 12 months and broadly consisted of five phases: recruitment; needs analysis; pilot studies; operations and management; guidelines and site finalisation. Key facets of each project phase can be summarised as:

- Recruitment: Students are recruited to undertake the set-up of a Faculty of Engineering podcasting unit and to pilot the first student-led, student-centred podcasts. Specific training is given to the students on podcasting technology and practice, science communication and interview methods by experts in the field. Student participation was entirely voluntary and the project was not associated with a specific class or course of study.

- Needs analysis: An examination of needs to determine the scope and goals of the podcasting program. In addition to forming ideas amongst the group itself, the team explores the views and desires of their peer group and academic staff on a podcasting activity. The group also

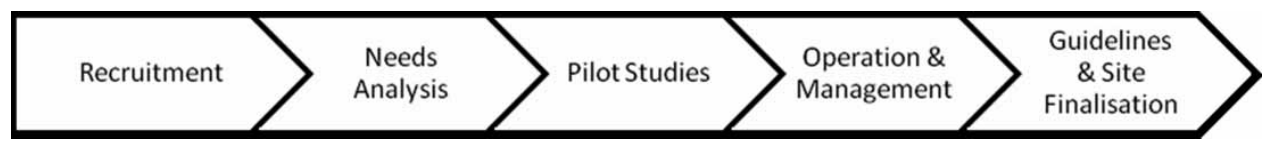

Figure 1. Workflow for the phases of the podcast project. 
identifies the resource and technology needs for podcast creation and editing as well as website management and development.

- Pilot studies: Once several podcasts on a variety of topics have been prepared (fully edited audio files with still images), they are be made available for students, staff and educationalists for their reviews and feedback. Two key podcasts are used for the detailed evaluation on the student impact. The first involves an educational piece on a core-engineering topic and the second a more general student matter. Attention is also given to the user-interface for downloading podcasts and the set-up of a free subscription service and, indeed, whether the site location is optimal for dissemination to engineering students and the broader campus community.

- Operations and management: Efforts focus on the preparation of podcasts, editorial aspects and sustainable management issues. This also involves a resource analysis for the ongoing delivery of podcasts.

- Guidelines and site finalisation: Based on the findings and recommendations of the team, the production of guidelines, remits and resource requirements for the ongoing management and running of a student-led podcasting unit.

Facilitators (an academic staff member and postdoctoral assistant) are involved in the early development of the team and to monitor the evolution of the podcasting project. Regular meetings are held with the student team and project management tasks and roles are identified early on in the needs analysis phase. Students are also encouraged to devise a plan to ensure that the first podcast trials are carried out within the first half of the project timeframe.

\subsection{Student organisational structure}

While generally the podcasting project is student-led and student-driven, it was necessary for the facilitators to introduce a basic organisational structure to the podcasting team. This helped to clarify the individual roles and responsibilities of the team members in order to move the project more rapidly into the needs analysis and pilot studies stages. The organisational structure of the student team is represented in Figure 2 and was in fact devised through consultation with

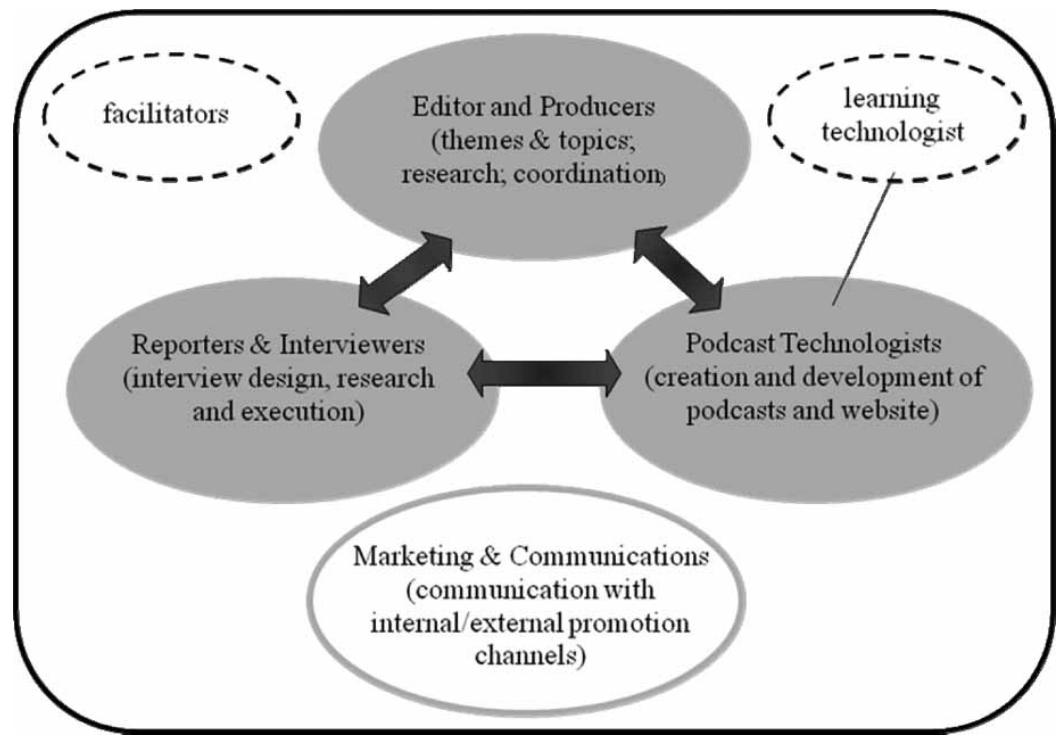

Figure 2. Schematic of the team organisational structure. 
the student team (see discussions below). The facilitators and the learning rechnologist serve as advisors to the team and are careful not to direct the operation of the group while still offering guidance and advice when necessary.

With reference to Figure 2, the podcasting team consists of four sub-teams: producers and editors; reporters and interviewers; podcast technologists; marketing and communications personnel. Each sub-team has a member appointed as the head who is responsible for conveying the sub-team's activities to the heads of the other sub-teams. The producers and editors sub-team is responsible for identifying and shaping the themes and topics and carrying out the research for the podcasts. The head editor is the overall team liaison and is responsible for giving progress updates to the facilitators. The reporters and interviewers sub-team is responsible for aspects related to interview design and organisation. This may include creating scripts/questions for interviews, maintaining and training others on the use of the audio recording equipment or conducting interviews themselves. The reporters and interviewers will frequently interact with the producers and editors sub-team and the podcast technologists, acting as the bridge that allows the concept to become a real podcast. The podcast technologists sub-team is responsible for creation and development of the podcasts (e.g. combination of audio and images using editing software such as Audacity) and managing and structuring the website for podcast downloading and viewing/listening. This product is given to the producers and editors to ensure that the podcast satisfies the original vision. The podcast technologists may also seek advice and guidance from the learning technologist on ways to make use of the existing technology resources within the college. Finally, the marketing and communications sub-team is responsible for promoting the efforts of the podcasting team and the website among the students of the Faculty of Engineering as well as the larger college community.

\subsection{Project evaluation}

Given the design and implementation premise of this project, in the first instance, evaluation focused on the experiences of the team members themselves. An evaluation form was devised to gauge the key learning outcomes of team membership and to attain open feedback on experiences. The design of the form was based on the initial student reasons for joining the project, as well as interviews with three students on the plus, minus and interesting aspects of the project experience. With reference to Appendix A, this information led to the design of a form that assessed three categories of impact: (i) skills development; (ii) education; (iii) community, as well as six additional free response questions. A 10-point Likert scale was used on 11 questions related to the three impact categories. Five additional (qualitative) questions provided students with a further opportunity for feedback and reflection on the experience. The form was distributed via email and anonymity assured through form submission to an administrator. Responses were attained from 10 of the 14 team members.

\section{Discussion}

\subsection{Implementation outcomes}

Having completed the 12 month project, one can comment on key lessons learnt during the project initiation, implementation and launch phases and thus on some good practice for the start-up of a student-led podcasting scheme. First, the recruitment of students to the podcasting project proved to be very easy. Engineering students at all undergraduate levels were invited to apply for a place in the team. Students were required to submit an application, which asked for course, year of 
study and a short statement of interest in the project. Students with a broad range of project interests and motivations were attracted to the podcasting unit concept. Motivations included experiences in journalism and science communication, as well as exposure to the technological aspects of podcast production. Additionally, some students indicated that they simply wanted to work with other engineering students to provide a podcasting service that would be listened to by students and staff alike and 'provide an entertaining and informative resource'. A maximum team size of nine was felt to be manageable in terms of internal organisation and would also allow one representative from each of the nine engineering departments within the Faculty of Engineering. However, because of significant student interest, the team size was increased to 14 students. Students did not receive any course credit; however, a nominal stipend was provided for their participation in the project.

After the team was formed, a 2-hour training session was given by a professional broadcaster (G. Mitchell, BBC World Service) on podcasting technology and practice, science communication and interview methods. In this session, the students were also exposed to the use of state-of-the-art recording equipment and audio editing software. The session also concentrated on team formation aspects, allowing students to share personal aspirations for the project and agreeing on ground rules to help foster open and supportive communication and interaction styles.

At the onset of the project, there was some concern as to the equipment requirements for high-quality podcast production and editing. However, after consultation with the professional broadcaster, the group were able to establish a minimum equipment inventory. Key hardware items include a professional digital recorder (Marantz PMD660), a high quality broadcasters' microphone (Beyerdynamic M58) and a microphone stand. Audio editing could be undertaken using free, open-source software (Audacity) and image-enhanced digital stories produced through a number of commercially available software, such as Camtasia and MS PowerPoint Producer for PC-based systems.

Initially, students were given much scope to develop the organisation and management structure of the group. However, this process was found to be rather difficult, mainly because of the large group size, the mix of students from different departments and the relatively ineffective email communications between the bi-weekly face-to-face meetings. After intervention from the facilitators, an organisational structure (Figure 2) was developed and sub-teams populated based on specific student interests. With the organisation solidified, the group began considering issues related to developing the team identity. Discussion was given to deciding on a team name and creating the team logo, which further helped to promote a strong student identity. For the former, members adopted a group and unit name as 'EPod', i.e. an acronym for engineering podcasting. A group page was also formed on the social networking site Facebook, which provided a single web location for sharing ideas and having virtual conversations between team (and sub-team) members. This was found to be a particularly powerful tool for group facilitation, increasing the frequency and quality of communications between meetings. Within Facebook itself, the organisation of the discussion forums mimicked the group organisation structure, thus effectively ordering the information flow. Nevertheless, through their own choice, the students produce formal minutes after each face-to-face meeting, which are forwarded to the facilitators for information and comment.

The needs analysis stage was facilitated by providing the students with a range of suggested topics for podcasts, so as to spur discussion and the brainstorming of ideas. Specifically, these topics included the sharing of student views on current political, global and scientific developments, which have a direct impact on the role and responsibilities of future engineers, the sharing of the experiences of senior students, alumni and teaching staff on learning matters (e.g. skills, learning approaches, stress management, career planning), providing a means for students to raise awareness and discussion on matters such as gender and cultural issues in engineering, providing engaging anecdotes on specific core engineering topics and providing a forum for disseminating information on student opportunities such as Undergraduate Research Opportunities 
Programme, Engineers Without Borders and other cross-faculty activities. The team also met with the Faculty of Engineering learning technologist to gather ideas to structure the main webpage with the interview/recording activities. The group decided to begin by offering access to the digital stories and interviews on a college-hosted website (http://www3.imperial.ac.uk/envision/ experiences/podcasting). Here, students and faculty in the College of Engineering and the broader campus community can listen directly to the podcasts or subscribe to the series of podcasts via a real simple syndication feed and iTunes. Summaries and transcripts of the podcasts, overall aims and objectives for the project and the podcast team's contact details are also made available on the website.

The pilot phase of the project involved trial interviews and subsequent audio editing. Although basic training on audio recording and interview technique was provided, these trials have proved to be a great learning opportunity for the students. Specifically, learning on how to capture sound in bustling student areas, how to engage and maintain the attention of interviewees under streetinterview situations and how to manage, label and categorise recordings for subsequent review and editing. In parallel to the pilot studies, operation and management issues have been further addressed, such as protocols for consistent product (podcast) design, equipment management and timetabling for a schedule of interviews and the website design that best promotes the material to a mixed cohort of engineering students.

The student team developed their initial two podcasts, one on a core engineering topic and the other focused on student-life topics. The team identified a few topics for the core engineering podcast but decided on photovoltaic technology as a first topic. Nuclear energy, water management and recycling are other topics of interest and are currently being researched by the team. For the student-life podcast, the team collated topic suggestions via a thread on their Facebook group. This extensive list includes student reasons/motivations for their specific engineering course, the teaching and learning experiences within the college, coping with study and exams and interesting, unusual or emerging career paths for engineers. Ultimately, the team selected a very timely topic on the impact of the recent departmental library closures. Summaries of the content of these podcasts are given in Table 1.

Students were asked to consider recommendations on funding and operational issues for the long-term sustainability of the unit. Specifically, this included the type and amount of regular resources needed, the management and organisation structures that maintain an effective interface between staff and students, as well as continuity from one management group to the next and mechanisms for ensuring that the podcasts maintain a balanced educational premise in line with faculty/college developments. These issues regarding sustainability and improvements to the operation and management of the podcasting unit were discussed amongst the team and with the

Table 1. Summary of the first two podcasts

Core engineering podcast: Photovoltaic cells

0:00 How did the idea of creating the team come along?

0:51 Could you describe your photovoltaic system?

1:42 What are the most difficult things that the team has encountered so far?

2:24 Could you describe the experience of the Rwanda trip in January 2009?

3:09 What is special about a student-led project?

4.39 About recruiting new members
Student life podcast: Departmental library closures

0:14 Why was it decided to shut down departmental libraries?

2:53 How will the central library deal with the influx of books?

5:11 Aren't the departmental libraries more accessible than the central library?

6:32 Aren't the departmental libraries more convenient?

6:59 Wouldn't the cost of opening departmental libraries during lunch offset the cost of opening the central library during the evening? 
facilitators. Formal feedback was also collected by an evaluation questionnaire at the end of the project (see below). Based on these recommendations, the organisational and support structures for the implementation of the podcasting unit are expected to be further refined as the unit moves from a set-up and development focus in this initial year towards one of team maintenance and ongoing student-body engagement in future years. Likewise, whilst the facilitators are able to realistically judge future resource requirements (which include nominal administration costs for arranging group meetings, website and learning technology support), ultimately budget control for ongoing and developmental work is to be passed to the students. As such, student ownership in the planning of resource and administration requirements is deemed important.

\subsection{Evaluation and student feedback}

Descriptive statistics for the responses to the EPod evaluation form are given in Table 2. The mean scores for the questions indicate an overall favourable evaluation across the categories of impact for the project. The responses with the highest mean values indicate that students felt a stronger sense of community amongst students in the Faculty of Engineering (Q10; mean $=80.0$ ) and had improved their links with other students $(\mathrm{Q} 9$, mean $=75.0)$ as a result of participation in the project. Additionally, the students perceive an improvement in the understanding of podcasting technology $(\mathrm{Q} 5$; mean $=78.0)$ and their teamwork skills $(\mathrm{Q} 3$; mean $=71.0)$. The lowest ranked mean scores showed that students perceived modest improvements to their science communication $(\mathrm{Q} 4$; mean $=58.0)$ and time management skills $(\mathrm{Q} 1$; mean $=64.0)$.

Figure 3 contains boxplots for individual question responses and for responses collated by category (i.e. skills development, education, community). For the latter, Cronbach alpha calculations indicated a good internal reliability for the items forming the skills development $(\alpha=0.72)$ and community $(\alpha=0.78)$ categories; the small number of items for the education category negated the use of the alpha calculation for this case. Similar to the mean results, interquartile ranges for both the individual and categorised responses illustrate favourable outcomes across all areas of impact. The top scoring questions are across the entire community category (Q8-Q11) and in skills development area for improved understanding of podcasting technology (Q5). These are very positive results, as community building was a key outcome that was aimed to achieve in development of this project and, of course, education in podcast technology is an essential facet for the operational success of the project. The relatively large score ranges for questions regarding

Table 2. Descriptive statistics for questions 1-11 of the EPod evaluation questionnaire.

\begin{tabular}{lrr}
\hline & Mean & SD \\
\hline Q1 & 64.0 & 9.7 \\
Q2 & 67.0 & 9.5 \\
Q3 & 71.0 & 14.5 \\
Q4 & 58.0 & 17.5 \\
Q5 & 78.0 & 16.2 \\
Q6 & 67.0 & 13.4 \\
Q7 & 71.0 & 9.9 \\
Q8 & 71.0 & 19.7 \\
Q9 & 75.0 & 16.5 \\
Q10 & 80.0 & 14.9 \\
Q11 & 71.0 & 11.0 \\
\hline
\end{tabular}

Note: Questions 1-5 denote the skills development category, 6 and 7 the education category and 8-11 the community category; $n=10$. 
(a)

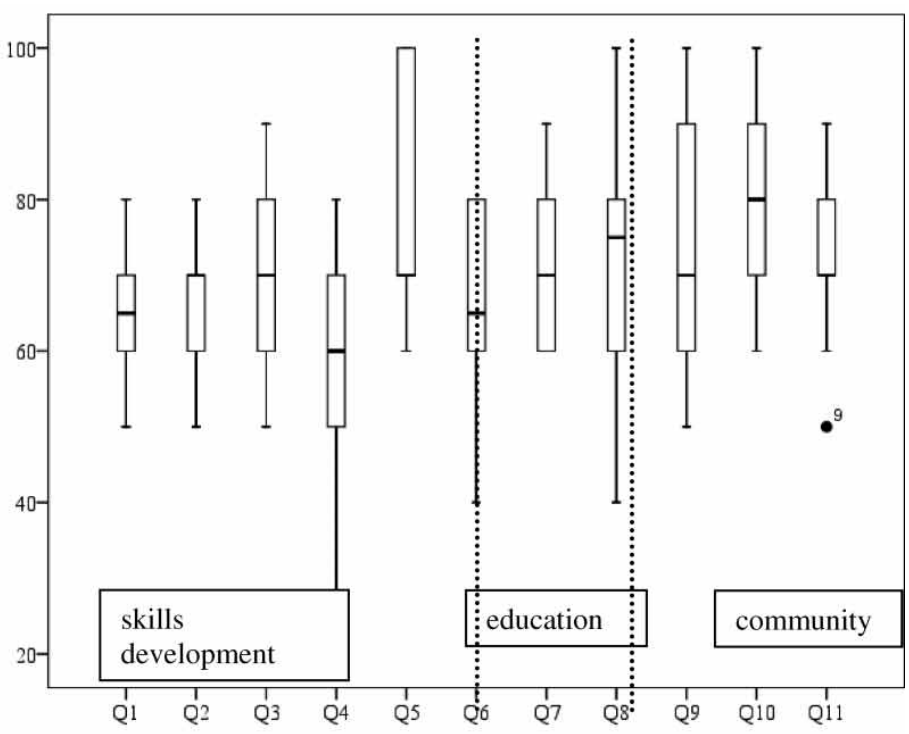

(b)

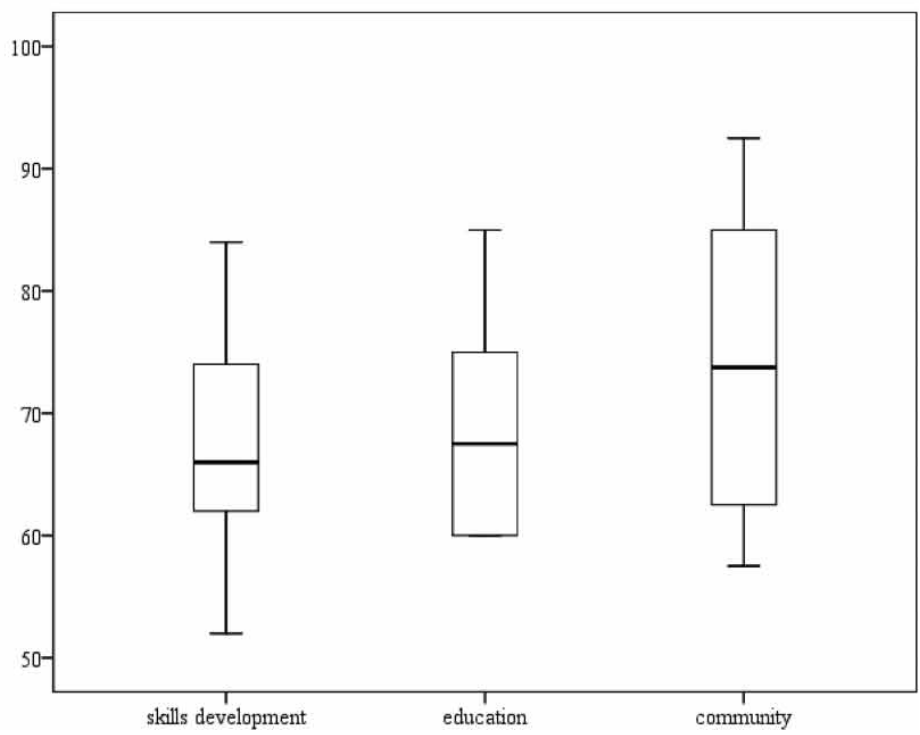

Figure 3. Boxplots for (a) questions 1-11 of the EPod evaluation questionnaire; (b) for questions categorised under skills development, education and community; $n=10$. Indication of internal reliability (Cronbach alpha) for the skills development and community categories only, i.e. $\alpha=0.72$ and 0.78 respectively.

improvements to science communication skills (Q4) and the broadening of awareness of important engineering issues (Q6) indicate that some students had higher expectations for these areas.

From answers to free response questions, many students expressed that their motivations and expectations were to produce enjoyable, relevant and educational podcasts for other engineering students, to learn the technical skills of podcasting and to broaden their knowledge of engineering issues not covered in traditional coursework. Others expressed that they hoped to get to know more Imperial students and improve their team-working skills. Overall enthusiasm for the project was evident throughout the responses and one student wrote that she/he 'hoped to start something big and exciting at Imperial and to learn more about media along the way'. The majority of the students indicated that their motivations and expectations overall were satisfied, though some expressed the 
view that the initial phases of the project moved slowly and they hoped to accomplish more. To this, one student appropriately remarked: 'being pioneers, it takes time to kick start something new'.

The students also offered suggestions of ways to improve the overall effectiveness of the team and project. Some students felt that communication needed to be improved and suggested to have more in-person meetings to supplement online communication. Many also felt that the roles and responsibilities of each team member within the four sub-teams should be outlined more explicitly such that everyone can be involved and the workload can be more balanced across the whole team. Others expressed that efforts toward building a stronger sense of team identity among members would also improve the project. Based on this feedback, it is intended to provide a second workshop for next year's podcasting team, focused solely on science communication (in addition to the podcasting technology workshop). Additionally, the facilitators will ensure that each team member has a distinct role and set of responsibilities within the sub-teams. About half of the team intend to continue on the project next academic year. The others have either graduated from Imperial or cannot participate due to other commitments.

\subsection{Current status}

In the 15 months since the set-up of the group, team recruitment has seen an expansion to 18 members. For management and communication purposes, the group has been divided into three subgroups, with members in each covering the roles identified in Figure 2. Each subgroup aims to produce one podcast per term, thus raising the overall productivity of the group. The most recent podcast, titled 'Engineering without borders: Looking to the future!' has to date had approximately 325 downloads, including many downloads from outside Imperial College and the UK. Over 200 listeners are currently subscribed to receive podcasts directly.

Resource requirements for the continuation of the project have been nominal. Access to a learning technology room for podcast editing and consumable costs associated with equipment batteries have been the only resource requirements. The release of each podcast is also associated with some minor administration time for checking the website upload and circulating an email advert to all engineering students on the new release. In terms of the volunteer, student-led premise of the project, student motivation for involvement in EPod as an extra-curricular activity has been high. Opportunities for creative and personal expression in podcast content and design have been a great incentive for student involvement, as has been the college-wide peer engagement of the produced podcasts. The Faculty of Engineering has also played a role here by endorsing EPod through the Faculty of Engineering website, i.e. an EPod webpage under the faculty's site. Overall, given the continued and indeed growing interest in engineering and student life-related podcasts (from both EPod volunteers and student subscribers) and the minimal resource requirements for the production and dissemination of such podcasts, the project has demonstrated the benefits and sustainability of a student-led podcasting approach.

Currently, the group themselves are considering the impact that the unit has had on the student engineering community (e.g. new awareness, improved engineering identity). A combination of student questionnaires, interviews and/or focus groups will be used to gauge student views on the quality, content and usefulness of specific podcast transmissions. Views on the quality and effectiveness of the podcasts will also be sought from senior faculty within the engineering departments at Imperial College.

\section{Conclusions}

The student-led podcasting project was developed as a new student resource and community for facilitating learning and communication across the Faculty of Engineering. It provides an 
innovative communication format for student engagement and involvement in educational topics, debates and developments among engineering students and faculty as well as the broader Imperial College community. At the same time, the team members themselves benefit from skills development in podcasting technology and science communication. The project design and organisational structures described in this paper have proved an effective means for the implementation of the podcasting unit. Student recruitment on the project proved easy, with motivations for involvement including interests in science communication, podcasting technology and working with peers to provide an entertaining and informative resource. A combination of face-to-face and web-based communication methods, clear student role and responsibility allocations and strong academic commitment to the podcasting unit has led to the successful set-up of the unit. An evaluation of the experiences of the EPod team members indicates favourable outcomes, especially in areas relating to the engineering community and identity, skills development in teamwork and podcasting technology and greater awareness of student-life issues.

\section{Acknowledgements}

The authors would like to acknowledge the financial support for this work through an Imperial College Teaching Development Grant. The authors would also like to thank Gareth Mitchell for his help and advice on the set-up of the group, Lauren Noto for her administrative and website development help and, of course, the student team from whom we've learnt so much, namely: Kamil Bayri, Cheng Chen, Erfang (Sunny) Chen, Shiang Chin, Dinesh Durai Ratnam, Nicholas Heung, Hassan Joudi, Kang Hao (Gillet) Li, Nida Mahmud, Majiroghene Otobo, Thusithan Puvaneswaran, Marc Schaepertoens, Jeremiah To, Wee Wong.

\section{References}

Alpay, E., et al., 2008. Engineering education developments through EnVision. Proceedings of the 7th annual ASEE global colloquium on engineering education, Washington, DC.

Armstrong, G.R., Tucker, J.M. and Massad, V.J., 2009. Interviewing the experts: student produced podcasts. Journal of Information Technology Education: Innovations in Practice, 8, 79-90.

Campbell, G., 2005. There's something in the air: podcasting in education. Educase Review, 40 (8), $33-46$.

Copley, J., 2007. Audio and video podcasts of lectures for campus-based students: production and evaluation of student use. Innovations in Education and Teaching International, 44, 387-399.

Dale, C., 2007. Strategies for using podcasting to support student learning. Journal of Hospitality, Leisure, Sport and Tourism Education, 6 (1), 49-57.

Edirisingha, P. and Salmon, G., 2007. Pedagogical methods for podcasts in higher education. LRA/BDRA demonstration file. Conference pre-print.

Frydenberg, M., 2006. Principles and pedagogy: the two P's of podcasting in the information technology classroom. Proceedings of ISECON 2006 [online]. Dallas, TX. Available from: http://www.isedj.org/isecon/2006/3354/ ISECON.2006.Frydenberg.pdf [Accessed August 2009].

Huntsberger, M. and Stavitsky, A., 2006. The new 'podagogy': incorporating podcasting into journalism education. Journalism and Mass Communication Educator, 61, 397-410.

Jenkins, M. and Lonsdale, J., 2007. Evaluating the effectiveness of digital storytelling for student reflection. ICT: Providing choices for learners and learning. Proceedings ASCILITE Singapore 2007 [online]. 440-444. Available from: http://www.ascilite.org.au/conferences/singapore07/procs/jenkins.pdf [Accessed August 2009].

Kao, I., 2008. Using video podcast to enhance students' learning experience in engineering. Proceedings of 115th annual ASEE conference and exposition [online], Pittsburgh, PA. Available from: www.asee.org/activities/ organizations/zones/proceedings/zone1/2008/Professional/ASEE12008_0131_paper.pdf [Accessed August 2009].

Lee, M.J.W. and Chan, A., 2007. Reducing the effects of isolation and promoting inclusivity for distance learners through podcasting. Turkish Online Journal of Distance Education, 8 (1), 1302-6488.

Lee, M.J.W., McLoughlin C. and Chan, A., 2008. Talk the talk: learner-generated podcasts as catalysts for knowledge creation. British Journal of Educational Technology, 39 (3), 501-521.

Liu, L., Huguet, M.-P. and Haley, T., 2008. Work in progress - SAGES: Podcast, wikis, and emerging technologies in the engineering classroom. 38th ASEE/IEEE frontiers in education conference, Saratoga Springs, NY. SEJ-13-14.

Maag, M., 2006. Podcasting and MP3 players: emerging education technologies. Computers, Informatics and Nursing, 24 (1), 9-13.

Mackey, K.R.M. and Freyberg, D.L., 2010. They learn, but enjoy it less, JEE selects, prism. American Society for Engineering Education, January, 49. 
McGarr, O., 2009. A review of podcasting in higher education: its influence on the traditional lecture. Australasian Journal of Educational Technology, 25 (3), 309-321.

Nie, M., Cashmore, A. and Cane, C. 2008. The educational value of student-generated podcasts. In: N. Whitton and M. McPherson, eds. Rethinking the digital divide. Research proceedings of the 15th association for learning technology conference (ALT-C 2008), 9-11 September 2008, University of Leeds, UK.

\section{Appendix A: Student-led podcasting for engineering education evaluation}

Please rate the following statements from 0 to 100 based on your degree of agreement using the following scale:

$$
\begin{aligned}
0 & =\text { strongly disagree } \\
50 & =\text { neither agree or disagree; } \\
100 & =\text { strongly agree. }
\end{aligned}
$$

\section{Skills development}

1. This project has improved my time management skills.

2. This project has improved my organisational skills.

3. This project has improved my teamwork skills.

4. This project has improved my science communication skills.

5. This project has improved my knowledge of podcast technology.

\section{Education}

6. This project has broadened my awareness of important $\quad \begin{array}{llllllllllll}0 & 10 & 20 & 30 & 40 & 50 & 60 & 70 & 80 & 90 & 100\end{array}$ engineering issues.

7. This project has broadened my awareness of important $\quad \begin{array}{llllllllllll}0 & 10 & 20 & 30 & 40 & 50 & 60 & 70 & 80 & 90 & 100\end{array}$ student life issues at Imperial College.

\section{Community}

8. This project has given me a stronger sense of identity as a $\quad \begin{array}{llllllllllll}10 & 20 & 30 & 40 & 50 & 60 & 70 & 80 & 90 & 100\end{array}$ member of Imperial College.

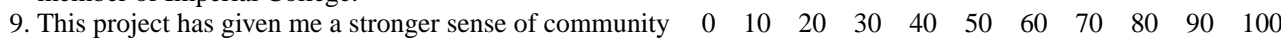
amongst students in the Faculty of Engineering.

10. This project has improved my links with other students. $\quad \begin{array}{llllllllllll} & 0 & 10 & 20 & 30 & 40 & 50 & 60 & 70 & 80 & 90 & 100\end{array}$

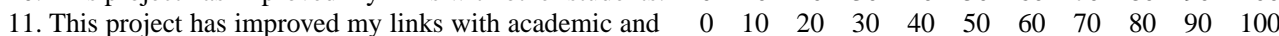
other staff.

What were your motivations and expectations in joining the podcasting project?

Have they been satisfied? Please explain.

How engaged did you feel in the podcasting project overall?

Do you plan to continue with the project next year?

What could be improved in the podcasting project?

Additional comments?

\section{About the authors}

Esat Alpay is a Senior Lecturer in Engineering Education. He holds a PhD in Chemical Engineering and an MA in the Psychology of Education. He has wide interests in the educational support and skills development of undergraduate 
and postgraduate students. Some of his current research and professional interests include: the development student transferable skills, creativity in design work, threshold concepts in engineering, peer assessment and peer-based learning, gender issues in higher education, the use of learning technologies for maths teaching and web-based labs. He is on the management team of EnVision, which is a cross-faculty team for the support and development of teaching initiatives.

Shelly Gulati obtained her B.S in Chemical Engineering from Johns Hopkins University and subsequently obtained her $\mathrm{PhD}$ from the University of California, Berkeley and University of California, San Francisco joint Graduate Group in Bioengineering. Her doctoral dissertation explored the fluid dynamics of DNA flows in novel small scale devices, termed microfluidic devices. She completed her postdoctoral research at Imperial College London in the Institute of Bioengineering investigating the detection and flow dynamics of micro-droplet reactors in microfluidic devices. At Imperial, Shelly was also involved in education projects which used podcasting technologies to enhance undergraduate education and provide an additional mechanism for mentorship of graduate students. She is currently a Lecturer in Applied Mathematics at the University of California, Merced. 